\title{
Myocardial Perfusion Imaging
}

National Cancer Institute

\section{Source}

National Cancer Institute. Myocardial Perfusion Imaging. NCI Thesaurus. Code C102676.

A procedure that captures pictures of blood flow throughout the heart muscle. 